\title{
Weaning of pigs : duodenal myoelectrical activity during the change from sow's milk to solid feed
}

\section{Violetta Leśniewska', S.G. Pierzynowski², Helle Nygaard Johansen², Mette Skou Jensen ${ }^{2}$ and B.B. Jensen ${ }^{2}$}

\author{
'Department of Animal Physiology, Faculty of Veterinary Medicine, \\ Warsaw Agricultural University \\ Nowoursynowska 166, 02-766 Warsaw, Poland \\ 'Department of Animal Nutrition and Physiology. \\ Danish Institute of Agricultural Science, Research Centre Foulum
}

DK-8830 Tjele, Denmark

\begin{abstract}
Duodenal electromyography (emg) was studied in conscious piglets during the suckling and postweaning period. In suckling piglets, emg showed regular, repeating migrating myoelectric complex (MMC) cycles, each of which was composed of the classical phases I, II and III. During the early postweaning period (1-10 days) feeding with solid feed influenced the duodenal emg. The duration of phase I after weaning was significantly shorter than that before weaning (3.3 vs. 10.6 $\min , \mathrm{P} \leq 0.01$ ), representing a decrease in duration from 14.6 to $4.6 \%$ of the wholc $\mathrm{MMC}(\mathrm{P} \leq 0.01)$. On the other hand, phase II increased from 79.9 to $89.6 \%$ ( $\mathrm{P} \leq 0.01$ ) after the change in diet. Feeding sow's milk did not disrupt the MMC pattern, however voluntary feed intake of solid feed induced continuous spiking activity of the duodenum for a period of $124 \mathrm{~min}$.
\end{abstract}

KEY WORDS: duodenal activity, piglets, weaning

\section{INTRODUCTION}

The motor/electric pattern of the stomach and small intestine is characterised by a triple phased migrating motor/myoelectric complex (MMC) that migrates distally along the length of the small intestine (Code and Marlett, 1975). The MMC is the endogenous rhythm of electrical activity in the small intestine, and it serves 
as the "housekeeper" of the gut, promoting bacterial clearance and maintaining intestinal homeostasis. The MMC appears rhythmically in the fasted state in some species, while in others, it appears rhythmically in the fed as well as in the fasted state (Wingate, 1981).

Weaning may be defined as the process by which mammals cease suckling and begin to ingest solid feed. In piglets, weaning induces enzymatic and structural changes in the digestive system. However, there have been no comprehensive studies of intestinal myoelectrical activity in neonatal piglets nursing with the sow, and it is not known how neonatal activity responds to weaning. This paper describes experiments in which the myoelectric activity of the duodenum in piglets was studied when they were suckling sow's milk and after the change to solid feed.

\section{MATERIAL AND METHODS}

Three, 29-30 days old Danish Landrace piglets $(6.3 \pm 1.5 \mathrm{~kg})$, were surgically fitted with a pair of silver bipolar electrodes (Sarna et al., 1982). The electrodes were implanted in the duodenum, 5-6 and 10-11 cm posterior to the pylorus. After weaning the piglets were fed a standard diet for growing piglets. During recording, the electrodes were connected to preamplifiers (BioAmp mkII, ADInstruments, Australia) with lower and higher cut-off frequencies set at 10 and $50 \mathrm{~Hz}$, respectively. The duodenal activity was continuously recorded using a digital-analogue recorder (MacLab 8e, ADInstruments). The signal was sampled at a frequency of 100 samples/s. The duodenal MMC was identified according to the criteria defined by Code and Marlett (1975).

The preweaning recordings were performed in the following manner:

feeding with sow's milk* ${ }^{*} \quad$ feeding with sow's milk*
1-1.5 h recording $1-1.5$ h recording

The postweaning recordings were performed in the following manner:

feeding with solid food*

$\Downarrow$

$1-2 \mathrm{~h}$ recording

$4 \mathrm{~h}$ recording

* the beginning of the feeding was assigned by the EMG recording (late phase I of $\mathrm{MMC})$ 


\section{RESULTS}

In all piglets, MMC activity was obscrved to resume by the fifth day following the operation. There were no differences in the baseline recordings between the animals. Table 1 illustrates the average recorded values for the piglets before and after weaning. Transition from milk to solid feed did not change the duration of the MMC cycle ( $69.8 \mathrm{vs} 68.8 \mathrm{~min})$. The duration of phase I was significantly shorter after weaning than before weaning ( $3.3 \mathrm{vs} 10.6 \mathrm{~min})$, representing a decrease in duration from 14.6 to $4.6 \%$ of the whole MMC. On the other hand, phase II increased from 79.9 to $89.6 \%$ after the change of the diet. Feeding with sow's milk (under natural frequency of nursing) did not disrupt the MMC pattern. The first phase III occurred 47.1 min after suckling, the period at which phase II (55.3 min, $\mathrm{P}=0.08$ ) appears in the "ordinary" MMC cycle, although the duration of the first phase III after suckling was longer ( 4.9 vs $3.8 \mathrm{~min}, \mathrm{P}<0.01)$ than in the "ordinary" MMC cycle. After weaning, however, ingestion of solid feed suspended the sequential patterns of $\mathrm{MMC}$, replacing the usual $\mathrm{MMC}$ by continuously spiking activity for $80-185$ min until the occurrence of a subsequent phase III front. The voluntary feed intake of solid feed during the recording time was $85.5 \pm 36 \mathrm{~g}$. The daily feed intake was $136 \pm 26 \mathrm{~g}$.

TABLE 1 Characteristic of duodenal myoelectrical activity in suckling piglets (before weaning) and during the immediate postweaning period

\begin{tabular}{lccccc}
\hline Cycle characteristic & Before weaning & \multicolumn{3}{c}{ After wcaning } \\
\hline & $\mathrm{x} \pm \mathrm{SD}$ & $\mathrm{n}$ & $\mathrm{x} \pm \mathrm{SD}$ & $\mathrm{n}$ & \\
Cycle duration, min & $69.6 \pm 8.2$ & 12 & $68.8 \pm 12.5$ & 14 & $\mathrm{P}=0.84$ \\
Length of each cycle & & & & & \\
Phase I, min & $10.6 \pm 8.9$ & 12 & $3.3 \pm 2.6$ & 14 & $\mathrm{P}<0.01$ \\
Phase II, min & $55.3 \pm 8.5$ & 12 & $61.7 \pm 11.9$ & 14 & $\mathrm{P}=0.13$ \\
Phase III, min & $3.8 \pm 0.6$ & 12 & $3.9 \pm 0.6$ & 14 & $\mathrm{P}=0.60$ \\
& & & & 14 & $\mathrm{P}<0.01$ \\
Phase I, \% & $14.6 \pm 11.6$ & 12 & $4.6 \pm 3.3$ & 14 & $\mathrm{P}<0.01$ \\
Phase II, \% & $79.9 \pm 11.1$ & 12 & $89.6 \pm 3.4$ & 14 & $\mathrm{P}=0.59$ \\
Phase III, \% & $5.5 \pm 1.3$ & 12 & $5.8 \pm 1.7$ & 8 & $\mathrm{P}<0.001$ \\
Activity after feeding, min & $47.1 \pm 8.3$ & 8 & $124.1 \pm 36.9$ & 8 & $\mathrm{P}<0.05$ \\
Ist phase III after feeding & $4.9 \pm 1.1$ & 8 & $3.3 \pm 1.0$ & & \\
\hline
\end{tabular}

\section{DISCUSSION}

The present investigation is the first to show the myoclectrical activity of the upper gut during the suckling period and during the first few days after weaning. Piglets prior to weaning receive $20-24$ regular meals per day of a very palatable, 
highly nutritious and digestible milk diet. Our study demonstrates that under these physiological conditions the MMC pattern is regular and independent of feeding with sow's milk. Burrows et al. (1986) reported that the myoelectrical activity of the jejunum, in conscious neonatal piglets fed cow's milk, was disrupted for about $80 \mathrm{~min}$ and that the cycles of MMC in the fasted state were irregular. In pigs fed solid feed the extent of disruption of basic intestinal motility pattern depends on the amount of feed consumed per meal: when pigs receive one large meal/d the pattern of electrical activity is disrupted for $6 \mathrm{~h}$. In pigs fed ad libitum the frequency of MMC cycles is similar to the fasted state (Ruckebusch and Bueno, 1976). It is possible that natural nursing piglets show no inhibition of $\mathrm{MMC}$ as the frequency of feeding and mother's milk may regulate this phenomenon (Hartmann and Holmes, 1989). At weaning there is a transformation from a complete nutritional and behavioural dependence on the sow to complete independence requiring different fecding and drinking patterns. Moreover, the profile of digestive enzymes and gastrointestinal $\mathrm{pH}$ in suckling piglets is inadequate to digest solid feed (Pierzynowski et al., 1990; Kelly et al., 1991). The long duration of continuous myoelectric activity after consuming solid feed could be a manifestation of functional adaptation of the bowel to the new type of diet. However, such a sharp change of the physiological motor activity of the small intestine might reduce digesta flow and mixing of digesta with digestive juices. This, in turn, could affect absorption and might allow the proliferation of enterotoxigenic bacteria, and thus affect animal health status and growth.

\section{REFERENCES}

Burrows C.F., Merrit A.M., Tash J., 1986. Jejunal myoelectrical activity in the conscious neonatal pig. J. Physiol. 374, 349-357

Code C.F., Marlett J.A., 1975. The interdigestive myoelectric complex of the stomach and small bowel of dogs. J. Physiol. 246, 289-309

Hartmann P.E., Holmes M.A., 1989. Sow lactation. In: J.L. Barnett, D.P. Hennessy (Editors). Manipulating pig production II, Australian Pig Science Association, Werribe, Victoria, pp. 72-97

Kelly D., Smyth J.A., MacCracken K.J., 1991. Digestive development in the early-weaned pig. II. Effect of level on food intake on digestive enzyme activity during the immediate postweaning period. Brit. J. Nutr. 65, 181-188

Pierzynowski S.G., Westrom B.R., Svendsen J., Karlsson B.W., 1990. Development of exocrine pancreas function in chronically cannulated pigs during 1-13 weeks of postnatal life. J. Pcdiat. Gastroenterol. Nutr. 10, 206-212

Ruckebusch Y., Bueno L., 1976. The effect of feeding on the motility of the stomach and small intestine in the pig. Brit. J. Nutr. 35, 397-405

Sarna S., Northcott P., Belbeck L., 1982. Mechanisms of cycling of migrating myoelectric complexes: effect of morphine. Amer. J. Physiol. 242, G588-G595

Wingate D.L., 1981. Backwards and forwards with the migrating complex. Dig. Dis. Sci. 26, 641666 